Emeritus Advisor in Pathology Imrich Friedmann

Advisors in Pathology Brian Manners, Christopher Milroy \& Lesley Smallman

Advisor in Audiology Linda Luxon

Advisors in Radiology Glyn Lloyd \&

Peter Phelps

Advisors in Statistics Anthony Hughes \& Peter Kelly

Production Editors Gillian Goldfarb \& Jennifer Almond

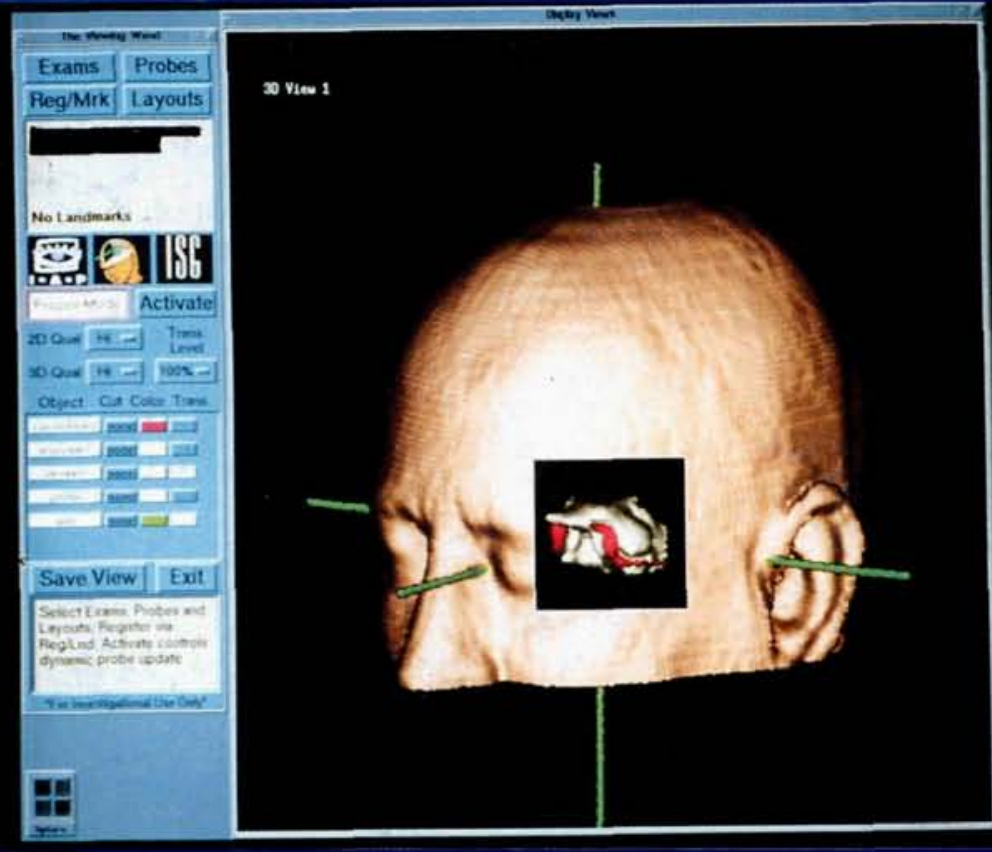

Th $\mathrm{e} \quad \mathrm{J} \circ \mathrm{u} \mathrm{r} \mathrm{n}$ a $\mathrm{l}$ of

Laryngology
\& Otology

$\underline{\underline{2=}}$

features:

Intra-operative image guidance in otolaryngology

Craniometaphyseal and craniodiaphyseal dysplasia

Value of lymph node biopsy in toxoplasmosis

Vocal fold palsy after use of the laryngeal mask airway

Fourth branchial arch fistula 


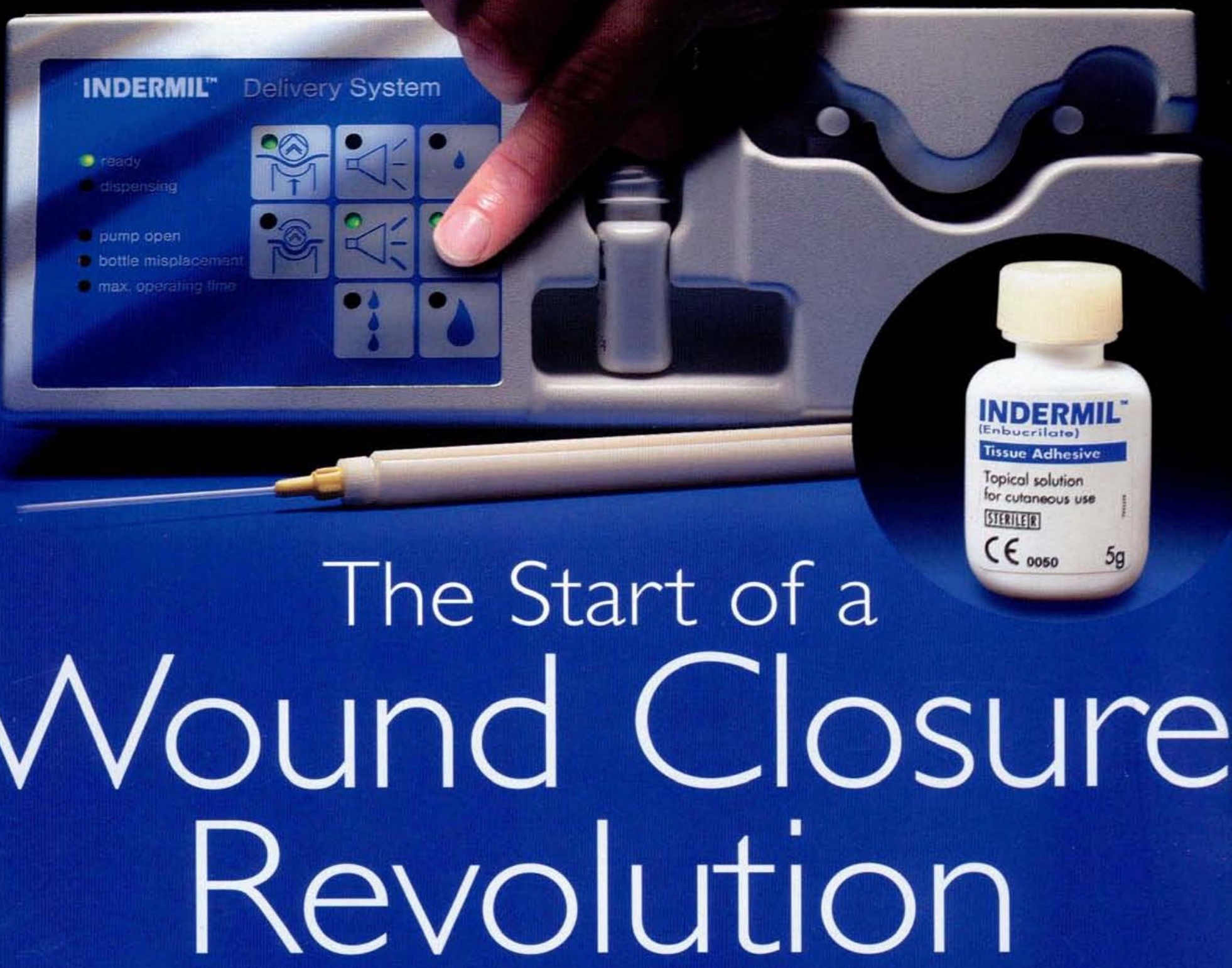

INDERMIL ${ }^{T M}$ is a revolutionary new wound closure system. For the first time, an advanced, gamma-sterilised, non-pigmented tissue adhesive has been combined with precision electronic delivery technology.

INDERMIL ${ }^{T M}$ adhesive allows rapid wound closure with minimal scarring and reduced risk of subsequent infection. Touchpad programmed delivery brings unprecedented accuracy and control.

Now wound closure can be less traumatic and more efficient than has ever been possible before. To discover the future of wound closure telephone 01707821255 or fax 01707821152 today.

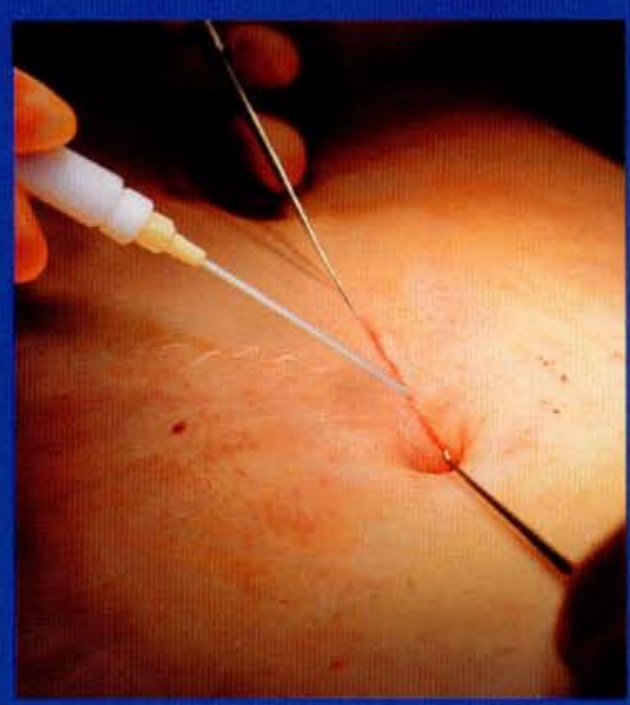

INDERMIL

Wound Closure Redefined
- RAPID - Accelerates wound closure procedure, maximising theatre time

- REDUCED SCARRING - Non-invasive. no tissue deformation, minimises scarring

- REDUCED TRAUMA - Reduces the trauma associated with conventional techniques

- REDUCED RISK OF INFECTION -

Can achieve complete tissue closure, reducing the risk of subsequent infection

- PRECISION - Unique adhesive delivery technology enables precise wound closure even in less accessible areas

\section{- EXTENDED SHELF LIFE}

Loctite UK Limited Biomedical Division

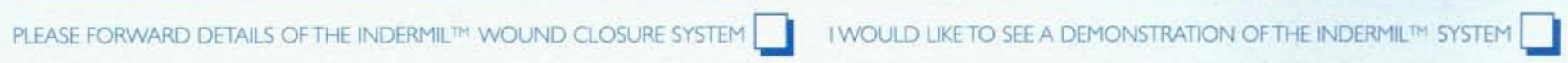




\section{The Journal of Laryngology and Otology

\author{
(Founded in 1887 by MORELL MACKENZIE and NORRIS WOLFENDEN)
}

Edited by NEIL WEIR

Assistant Editors CAROL WENGRAF, RICHARD RAMSDEN, DAVID PROOPS, VALERIE LUND, HENRY GRANT, ANDREW JONES, GUY KENYON MICHAEL ROTHERA, MARTIN BAILEY, LIAM FLOOD, PATRICK BRADLEY \& NICK JONES

Production Editors GILLIAN GOLDFARB \& JENNIFER ALMOND

\section{INSTRUCTIONS FOR AUTHORS}

1. Original articles which have not been published elsewhere are invited and should be sent to the Editor. They are considered for publication on the understanding that they are contributed to this Journal solely. Reproduction elsewhere in whole or in part, is not permitted without the previous written consent of the Author and Editor and the customary acknowledgement must be made. Normally an original main article should not exceed 7500 words.

Longer articles or theses will be considered for publication as Supplements, at the expense of the authors or their employing authorities.

2. Manuscripts should be typewritten in duplicate on one side of the paper only (A4 $2973210 \mathrm{~mm}$ ) and double spaced, with wide margins.

Begin each component on a new page in the following sequence: title page, abstract, text, acknowledgements, references, tables and legends.

(a) Title page-Titles should be short with names of the authors, higher degrees only. Details of the departments in which the authors work should be put lower down. An address for correspondence should be supplied together with the author who should receive this; this will ultimately appear beneath the list of references. Any change of address should be notified. If the paper was presented at a meeting, the details of this must be given and will be inserted at the bottom of the first page of printed script.

(b) Abstract-This should contain not more than 150 words and include a statement of the problem, the method of study, results and conclusions; a 'summan' section should not be included in the main manuscript. No paper will be accepted without an abstract.

(c) Key Words-Only those appearing as Medical Subject Headings (MeSH) in the supplement to the Index Medicus may be used; where no appropriate word(s) are listed those dictated by common sense/usage should be supplied.

(d) Text-Suggested outline-(1) introduction, (2) materials and methods, (3) results, (4) discussion, (5) conclusion.

(e) Tables are adjuncts to the text and should not repeat material already presented.

(f) Illustrations - Two sets of illustrations, one with each copy of the manuscript, must be submitted and all authors should remember that the single column width is

$80 \mathrm{~mm}$. One set of illustrations should, therefore, not exceed this width and they should ensure that the essential features are illustrated within this dimension.

Coloured illustrations will be charged to authors, unless a special grant is authorized by the Editor.

Written permission from the publisher must be provided to the Joumal in order to republish material with copyright elsewhere and also from the senior author where necessary. Consent to be obtained from a patient if a photograph of their face is to be reproduced.

(g) Measurements must be in metric units, with Système Internationale (SI) equivalents given in parentheses.

(h) References-For Journal articles, The Harvard system of recording references should be used, e.g. Green, C. and Brown, D. (1951) The tonsil problem. Joumal of Laryngology and Otology 65: 33-38. A paper written by more than two authors should be abbreviated in the text, e.g. Green et al. (1951), but all the authors should be given in the list of references. The titles of all Journals should be given without abbreviation. References should be listed in alphabetical order; use of the Vancouver system will not be accepted.

For single-author books, the following style should be used: Green, C. (1951) The tonsil problem, 2nd Edition. vol. 1, Headley Brothers Ltd., Ashford, Kent, pp 33-38. For papers in multi-books with one or more editors, the reference should include the title of the chapter and the names of the editors, together with the number of the edition as e.g. Brown, D. (1951) Examination of the ear. In Diseases of the Ear, Nose and Throat. 2nd Edition. (White, A., Black, B., eds.), Headley Brothers Ltd., Ashford, Kent, pp 33-38.

It is most important that authors should verify personally the accuracy of every reference before submitting a paper for publication. The names of authors cited in the References should be given in alphabetical order.

(i) Drugs-The proper names of drugs must be used. One reference can be made to the brand name if it is felt to be important to the study.

(i) Financial disclosures - In the submission letter to the Editor, the authors must list all affiliations with or financial involvement in, organizations or entities with a direct financial interest in the subject matter or material of the research discussed in the manuscript.

(k) Declaration. Each manuscript must be accompanied by a letter of declaration to be signed by each author to confirm that they have seen, read and approve the contribution bearing their name.

(1) Rejections -All manuscripts which are rejected will no longer be returned to the authors. Those submitting papers should, therefore, ensure that they retain at least one copy and the reference numbers, if any, of the illustrations. The only exception to this will be those manuscripts with colour illustrations which will be returned automatically by Surface Mail.

(m) Facsimile (FAX-All authors should send a Facsimile number whenever possible to speed communication; this particularly applies to those outside the United Kingdom. Manuscripts with no visual illustrations ( $X$-rays/pathology) may be sent by facsimile.

3. Page proofs are sent to authors for corrections, which should be kept to a minimum; they must be clearly marked, and no extra matter added. Proofs should be returned within 5 days.

4. Orders for reprints must be sent when returning page proofs, and for this purpose special forms are supplied.

5. Editorial communications may be addressed to The Editor, Joumal of Laryngology and Otology, c/o Headley Brothers Ltd., The Invicta Press, Ashford, Kent

TN24 BHH, or sent by FAX $(01483$ 451874).

6. The annual subscription is $\mathbf{\$ 1 0 0 . 0 0}$ Institutions \& Libraries US\$230.00; $\mathbf{8 8 5 . 0 0}$ Individuals US\$195,50; $\mathbf{2 4 5 . 0 0}$ Registrars, Residents and Interns. (Those in training should submit a certificate from The Head of the Department giving details of their appointment; those who qualify must supply their home address for mailing direct). Claims to be made for missing issues within 6 months of each publication date.

7. Single copies of current or back numbers (when available) will be on sale at $\$ 12.00$ each (including postage).

8. SUPPLEMENTS published at 'irregular' intervals with subscription, available separately on request.

9. All subscriptions, advertising and business communications should be sent to the publishers, or subscription agents.

HEADLEY BROTHERS LTD, THE INVICTA PRESS, ASHFORD, KENT

$$
\text { (C) Journal of Laryngology and Otology Ltd., } 1996 \text { ISSN 0022-2151 }
$$

Second class postage paid Rahway, N.J.

Postmaster: Send address corrections to The Journal of Laryngology and Otology, c/o Mercury

Aiffreight International Ltd. Inc., 2323 Randolph Avenue, Avenel, N.J. 07001. Frequency of Publication: Monthly.

\section{Instructions for Occasional Articles}

Review Articles. Articles of this type, preferably not exceeding 3,000 words will be considered but the author(s) are expected to be a recognized authority on the topic and have carried out work of their own in the relevant field.

Historical Articles. Articles of this type are generally encouraged, but it is obvious that they have to provide some new information or interpretation, whether it be about a well-known person or for example an instrument associated with him, but those from within a Hospital's own department who have made a hitherto less well-known contribution would be welcome.

Audit Articles. Articles should be of general audit interest-not specifically departmental. It should always be demonstrated that the 'audit cycle' has been completed.

'silence in Court'. Articles on medicolegal topics are welcome but a preliminary letter written beforehand is requested to ensure that the contribution would be 'Silence in

Short Communications. This feature will be used on an occasional basis. Examples of material suitable for inclusion under this title would be, for example, a piece of work which was of clinical interest but had failed to produce findings which were of statistical significance; where an investigative technique has been applied to an allied field, not warranting a further in-depth description of its earlier application and methodology.

Radiology in Focus. Short reports on cases in which the radiology has been crucial in the making of the diagnosis or the management of a particular case now appear on a monthly or bimonthly basis. This spot is to encourage clinicians and radiologists to produce material of particular interest in the specialty and to encourage co-operation in this field. Only presentations with first-class illustrations can be accepted and these must emphasize a probiem of unusual clinical interest. Pathology in Focus. Articles which are of pathological interest with particular emphasis on the way the diagnosis was achieved now appear on a monthly or bimonthly basis. It is hoped that clinicians will involve their pathologists in these reports, and all illustrations must be of first-class quality. Where a department, particularly those overseas, may not have such specialized facilities. It may be possible, if a block or several unstained sections are provided for our Adviser to produce or supplement the illustration submitted. Only contributions of particular pathological interest will be accepted.

or supplement the illustration submitted. Only contributions of particular pathological interest will be accep

Letters to the Editor. This feature has been re-introduced to give those who wish to comment about a paper previously published within the Journal, an Letters to the Editor. This feature has been re-introduced to give those who wish to comment about a paper previously published within the Journal, an
opportunity to express their views. Wherever possible, the original author is asked to add his further comment, thereby adding to the value of the contribution. Such letters should be sent as soon as possible after publication of each month's issue of the Journal in the hope of including them early thereafter.

'Mini-papers', such as those which appear in the British Medical Journal, Lancet, or New England Journal of Medicine, will not be acceptable except on the rare 'Mini-papers', such as those which appear in the British Medical Journas 


\section{EVERY MONTH... THE BEST IN ENT}

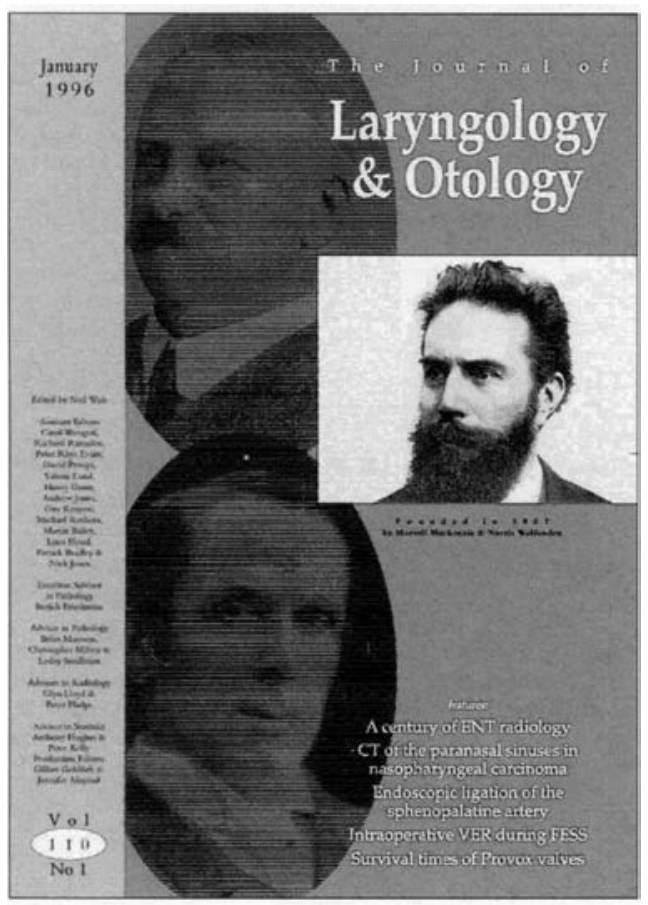

he Journal of Laryngology and Otology was the first
British journal in the ENT field. Since 1887, it has remained the definitive information resource for surgeons, consultants and students. The Journal is run as a charity to promote education and knowledge in all spheres of Laryngology, Rhinology, Otology and related fields.

he JLO is very much an international journal with
contributors from around the world and readers from over 80 countries.

he JLO contains main Articles, case reports and short
communications from all over the world. Other contents include the quarterly book review, selected abstract service, and every ten years there is a comphrehensive index issue published. By subscribing to the JLO, you not only gain everyday access to this valuable source of information, but also assist in the promotion of excellence in the ENT domain.

\section{The Journal of Laryngology and Otology}

I wish to subscribe to the JLO for one year (12 issues)

Please tick one:

Standard Rate $£ 85$

Standard Rate U.S. \$195.50

Registrars, residents and interns Rate $£ 45$ (with confirmation of status from head of department)

Bill me

Cheques must be in pounds sterling or US dollars drawn on a US bank payable to Headley Brothers Ltd.
Name:

Address:

City: Postal Code

Country:

Grade:

Mail to: Subscription Department Journal of Laryngology and Otology Headley Brothers Ltd The Invicta Press

Ashford, Kent TN24 8HH ENGLAND

or Fax to: +441233612345 


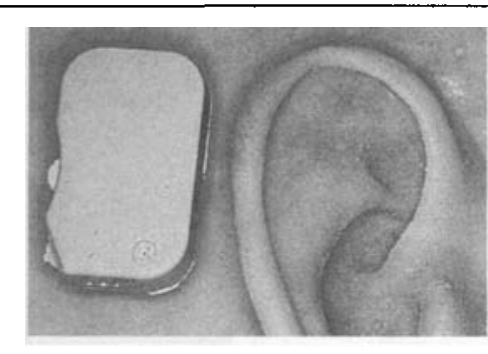

$\ldots a$

development

of the Bone

Anchored

Hearing Aid.

\section{BAHA Classic 300}

The updated BAHA has three main improvements:

The first is the development of a continuous base tone control which has flexibility to cover the frequency response range of the four previous models.

The second improvement is the adoption of ABS plastic for the hearing aid casing which offers a more aesthetic moulded design, greater strength and colour stability.

The BAHA Classic 300 also comes With a Five Year WARRANTY.

Indications for the BAHA

- Chronic Otitis Media - with conductive or mixed hearing loss where the use of air conduction devices is contraindicated.

- Congenital Malformation - of the external or middle ear where an air conduction hearing aid cannot be used or is contraindicated.

Otosclerosis - in some cases

For further information

contact Michael Mercer on tel. +44 (0) 1895430650 .

\section{N Nobelpharma}

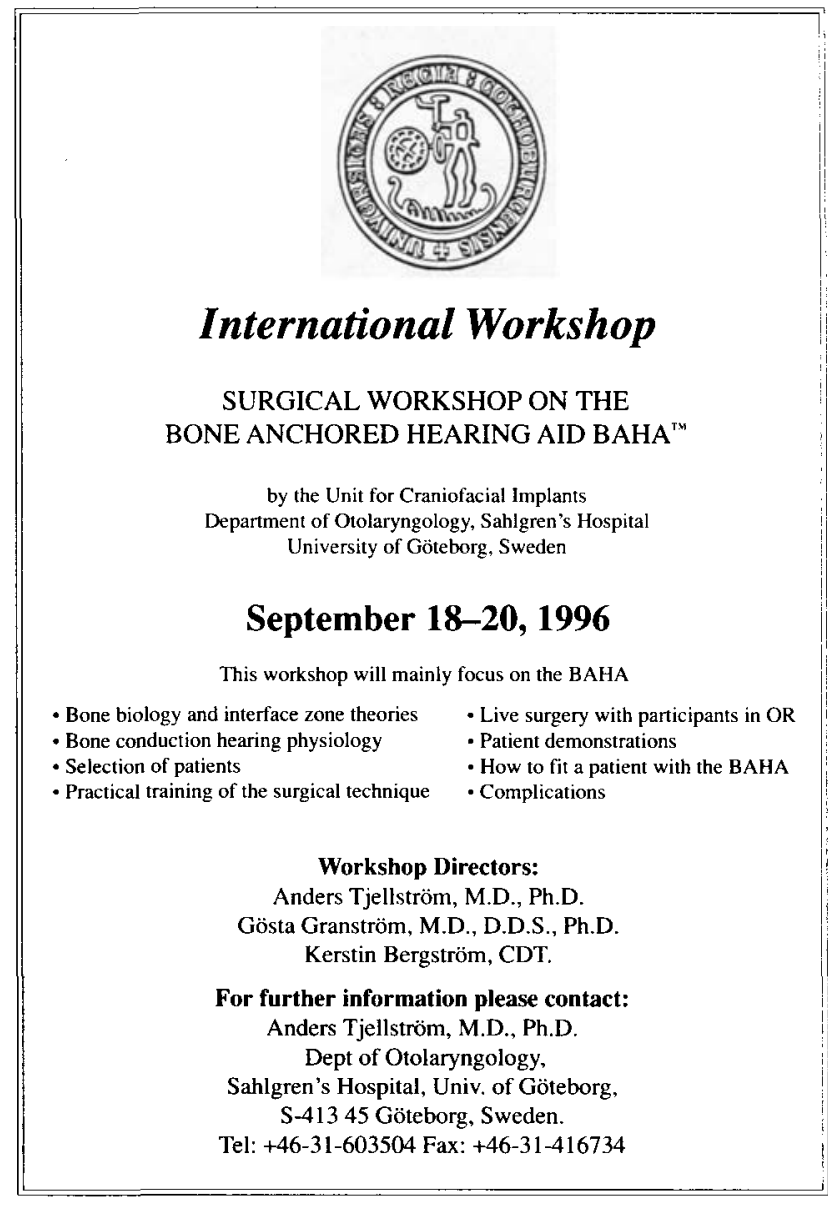

- Bone biology and interface zone theories

ery with participants in $O R$ Patient demonstrations

- How to fit a patient with the BAHA - Selection of patients

Workshop Directors:

Kerstin Bergström, CDT

further information please contact:

gren's Hospital, Univ, of Göteborg.

S-413 45 Göteborg, Sweden.

+46-31-603504 Fax: +46-31-416734

\section{THE VOROSCOPE COAXIAL}

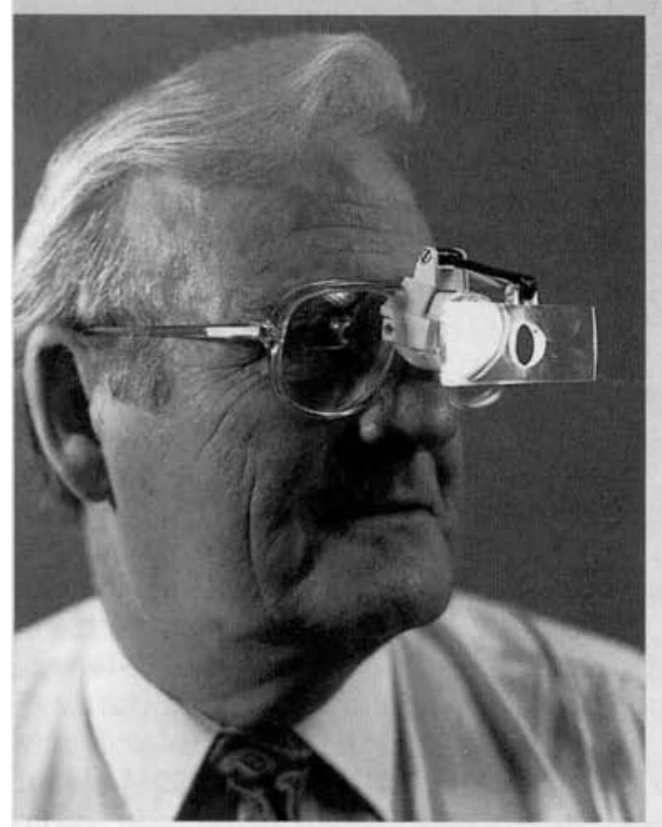

makes light of those LITTLE problem areas. by providing:

* EyE-Aligned Illumination OF 12,000 LUX AT ONLY 85g.

* belt clip battery and complete mobility.

* CONTINUOUS USAGE CAPABILITY.

* VARIable magnification of $\mathrm{X} 1.5, \mathrm{X} 1.75$ AND X2.25

* eye strain and fatigue relief.

* LOW COST AND CONVENIENCE

* PREscription lenses if ReQUired.

* availability in either black or white.

* IDEAL FOR USE IN THEATRE, ClINIC, WARD, CONSULTING ROOM, EMERGENCY AND DOMICILIARY CALLS.

\section{$\begin{array}{lllllllllllllllllllllllll}G & A & R & T & H & J & E & S & S & A & M & I & N & E & H & E & A & L & T & H & C & A & R & E\end{array}$}

Unit 5, The Courtyard, Matthewsgreen Farm, Matthewsgreen Road, Wokingham, Berkshire, RG41 1JX Telephone: (01734) 786916. Facsimile: (01734) 774064 


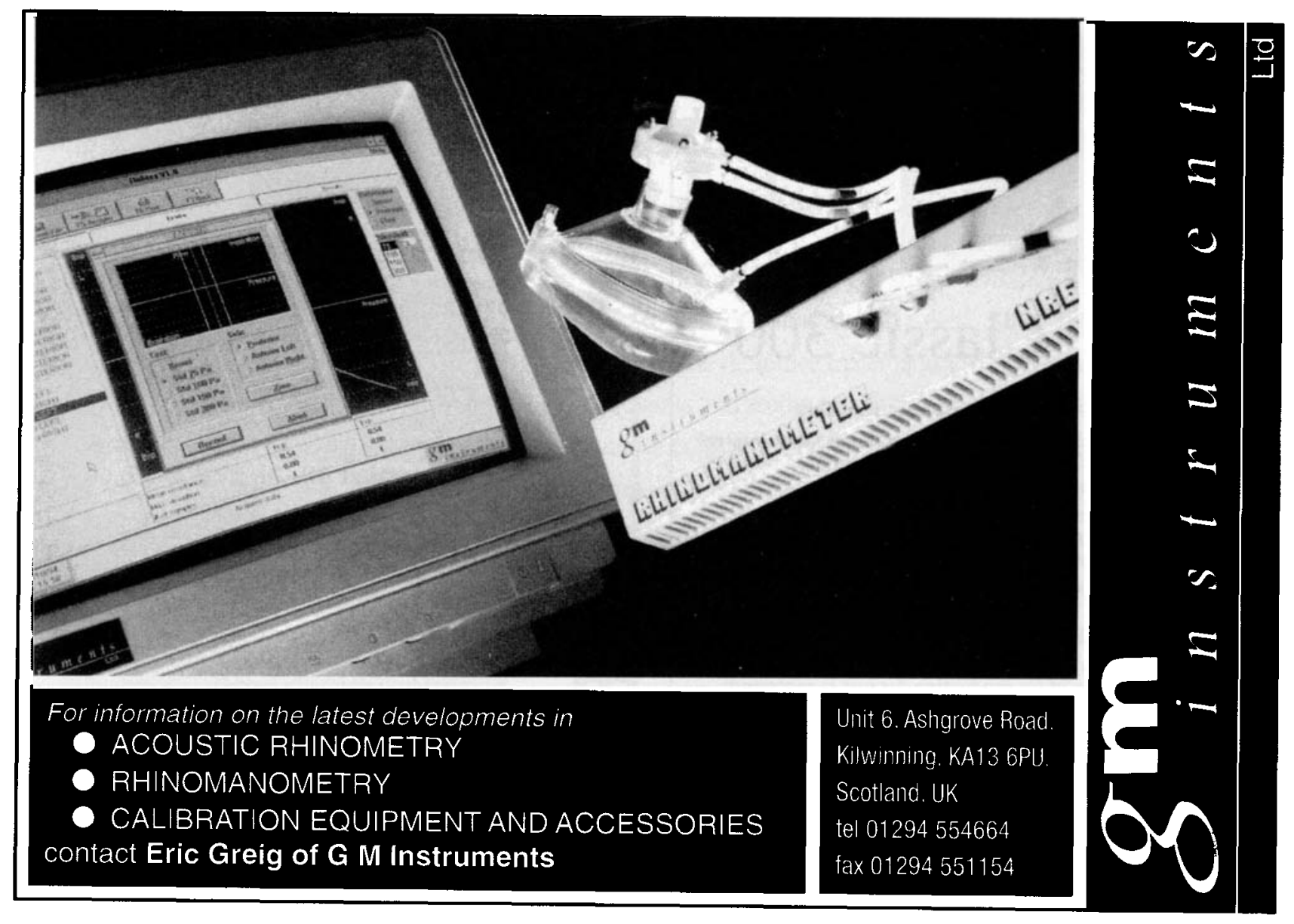

\section{Excellent}

\section{small-power}

hearing

aids

for

young

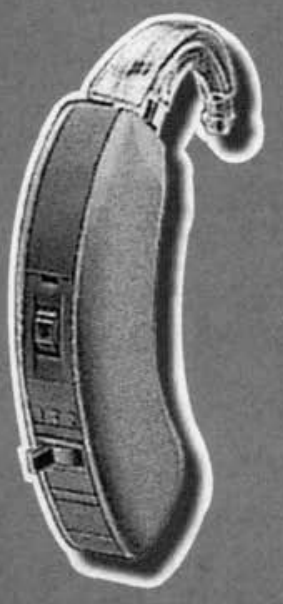

\section{Consider these post-aural hearing aids.} Features of the Ikon AoHPs include:

- Power (82db gain 140db output) with extended battery life up to 230 hours - M-T-O or M MTO Switching $\bullet$ Earhooks, filtered, unfiltered and child-size - Direct Audio Input facilities plus Euroshoes - Tamper Proof Volume Controls and Battery Trays The Ikon series features coloured side-plates - on request. Programmable versions are available.

\section{SEND FOR OUR INFORMATION PACK}

Name

Address

Country.

Specialty.

\section{Postal Code}

\section{Ю BOMMER UK}

Limited

Unit 5, Gatwick metro Centre or FAX

Horley, Surrey RH6 9GA United Kingdom

Tel: 01293821000 Fax: 01293821010 